\title{
BMJ Open Structural and functional support among US older adults with asthma: cross-Sectional associations with medication adherence
}

\author{
Rachel O'Conor, ${ }^{1}$ Jeni Hebert-Beirne, ${ }^{2}$ Mary Kwasny, ${ }^{3}$ Kamal Eldeirawi, ${ }^{4}$ \\ Romana Hasnain-Wynia, ${ }^{5}$ Juan Wisnivesky, ${ }^{6}$ Michael Wolf, ${ }^{7}$ Alex Federman ${ }^{6}$
}

To cite: O'Conor R, HebertBeirne J, Kwasny M, et al. Structural and functional support among US older adults with asthma: cross-Sectional associations with medication adherence. BMJ Open 2019;9:e027430. doi:10.1136/ bmjopen-2018-027430

- Prepublication history and additional material for this paper are available online. To view these files, please visit the journal online (http://dx.doi. org/10.1136bmjopen-2018027430).

Received 22 0ctober 2018 Revised 12 June 2019 Accepted 24 July 2019
Check for updates

(C) Author(s) (or their employer(s)) 2019. Re-use permitted under CC BY-NC. No commercial re-use. See rights and permissions. Published by BMJ.

For numbered affiliations see end of article.

Correspondence to Dr Rachel O'Conor; r-oconor@northwestern.edu

\section{ABSTRACT}

Objectives Disadvantaged older adults may benefit from social support in adhering to their medications, but the multidimensional nature of social relationships makes it difficult to identify the most relevant domain. We examined associations of structural and functional support with medication adherence among a cohort of older adults with asthma.

Design Cross-sectional analysis of the Asthma Beliefs and Literacy in the Elderly cohort study.

Setting Outpatient clinics in New York, New York, and Chicago, Illinois, USA.

Participants English-speaking and Spanish-speaking older adults ( $\geq 60$ years) with asthma.

Outcome measures Medication adherence was measured using dose counts from inhaler and self-report. Results Among 383 participants, the mean age was 67 years, $38 \%$ identified as Hispanic, $33 \%$ identified as black, $52 \%$ reported monthly incomes $\leq$ US $\$ 1350$ and $64 \%$ demonstrated poor adherence to their asthma controller medication. Structural and functional support were weakly correlated ( $r=-0.15, p=0.005)$. In adjusted analyses, structural support was not associated with medication adherence. Participants who received infrequent functional support in managing their medications had lower odds of poor adherence according to dose counts (OR $0.51,95 \% \mathrm{Cl}$ 0.26 to 0.98 ), but not when assessed via self-report ( $O R$ $0.81,95 \% \mathrm{Cl} 0.44$ to 1.48 ).

Conclusion The receipt of frequent functional support in managing medications was associated with poor adherence to asthma controller medications. Further research is needed to better understand the manner and context which functional support operates in relation to medication adherence among older adults.

\section{INTRODUCTION}

Socially and economically disadvantaged older adults who are known to have low rates of medication adherence, ${ }^{1-3}$ due to numerous barriers accessing and taking often complex regimens, ${ }^{4-6}$ may benefit from social support as they seek to manage their medications. Social relationships are commonly distinguished by the structure or function of
Strengths and limitations of this study

- We examined associations between social support and medication adherence among older adults and populations experiencing social and economic hardship; our population is unique among studies examining associations between social support and health behaviours.

- We conducted a secondary data analysis of a cohort study; we are therefore limited by the included measures that were not original intent of the aims.

- Our measure of functional support was not previously validated; however, we were not aware of any medication-specific functional support measures.

- We conducted cross-sectional analyses and therefore we are limited in understanding directionality of these associations, and we cannot infer causality.

the support provided, and are categorised as structural or functional support. Structural support refers to the size and extent to which individuals are integrated within their social network, and examples include marital status, social network size and social isolation. Conversely, functional support encompasses the specific utility provided by the relationships. ${ }^{7}$ Functional support is further classified into four types of social support, which include: 1) emotional, expressions of caring, 2) informational, the provision of information, 3) tangible, the provision of direct material aid or other concreate assistance and 4) belonging, having others to engage with in social activities. ${ }^{7}$ The multidimensional nature of social support makes it challenging to identify the most relevant dimension related to medication-taking behaviours to act on. ${ }^{78}$ Further complicating this understanding is the paucity of literature among low-income and racially and ethnically diverse older adults related to social support and medication adherence. A recent systematic review 
detailing associations between medication adherence and social support only identified a few investigations among older adults, and none were among older adults facing significant social and economic hardship. ${ }^{9}$ The review overall did not observe consistent associations among the studies that measured structural aspects, while the few studies that assessed functional support in terms of the tangible assistance that was provided did observe a consistent positive relationship with medication adherence, but these measures were variable and not always aligning with specific medication-taking behaviours that may be most beneficial to promoting medication adherence. ${ }^{9}$

While there is a growing recognition of the benefits functional support (tangible support in particular) may provide in promoting medication adherence, no evaluation to our knowledge has compared functional versus structural support to ascertain what is more likely to facilitate medication adherence among a diverse older sample. ${ }^{10} 11$ The Asthma Beliefs and Literacy in the Elderly (ABLE) cohort provides an opportunity to investigate this as measures of structural and functional support and medication adherence were collected. The cohort is particularly relevant as the sample is comprised of socioeconomically and culturally diverse older adults who were managing multiple chronic conditions, in addition to asthma. Medication adherence for asthma can be particularly challenging as individuals often use multiple inhalers which requires the deployment of multiple steps and coordinated actions, compared with the simpler task of taking tablets or capsules, ${ }^{12}$ and must also discern which inhaler to use under different circumstances (controller medicines are prescribed daily to reduce inflammation in the lungs, while rescue medicines are prescribed to be taken on an as-needed basis). ${ }^{12}$ Therefore, we sought to investigate associations between structural and functional support and medication adherence in the ABLE cohort. It was hypothesised that functional support, and not structural support, would be associated with medication adherence, and that less frequent functional support related to medication management would be associated with poorer medication adherence.

\section{METHODS}

\section{Sample}

We conducted a cross-sectional secondary data analysis with data from a National Heart, Lung and Blood Institute funded study, Asthma Beliefs and Literacy in the Elderly (ABLE; R01HL096612). A full description of the cohort has previously been published. ${ }^{13}$ Briefly, the sample was recruited from outpatient practices in New York City, New York and Chicago, Illinois from December 2009 through May 2012. Potential participants were identified through queries of clinic records and contacted via telephone by trained research coordinators to assess eligibility. Interested and eligible participants were scheduled for an in-person baseline interview. Patients were eligible to participate if they: 1) were aged 60 years and older, 2) spoke English or
Spanish and 3) had moderate or severe persistent asthma. ${ }^{12}$ Exclusion criteria included a chart-documented or self-reported diagnosis of chronic obstructive pulmonary disease (COPD) or other chronic respiratory illness or self-reported smoking history of $\geq 10$ pack-years because they are at increased risk of COPD. We identified a total of 1972 patients; successfully contact 1,506 and screened 1025, of whom 502 were eligible. Of these, 452 participants were enrolled and provided written consent.

\section{Measures}

\section{Medication adherence}

Adherence was measured through a review of the analogue dose counters on participants' inhalers over a 30-day period. Research staff reviewed the device to collect an initial reading during the baseline interview, and then contacted participants by telephone 30 days later to record the number of doses remaining. Research staff also documented whether the participant had started a new device. Research staff attached a Doser CT (Meditrack, Hudson, Massachusetts, USA) electronic monitoring device atop metered dose inhalers that did not have counters built into the inhalers. The Doser CT electronically recorded the number of times the device was used each day, and participants returned the electronic device to the study team by mail. Adherence was calculated by the total doses taken divided by the total doses prescribed during the 30-day period, and participants were classified as poor or adequate adherence. Poor adherence was defined as $80 \%$ or less of expected doses recorded, following a commonly applied threshold. ${ }^{1415}$

Medication adherence was also collected via self-report with the Medication Adherence Reporting Scale for Asthma (MARS-A). The MARS-A is a validated, 10-item measure previously adapted to assess adherence with asthma medications and is correlated with an objective electronic monitoring measure of adherence. ${ }^{16}$ The scale examines both intentional and non-intentional aspects of medication adherence, and the questions are framed as a negative statement to minimise social desirability bias. Each item is rated on a 5-point Likert scale with higher scores indicating greater adherence. Participants with a MARS-A score of $<4.5$ are classified as having poor adherence to daily asthma controller medications, which is equivalent to sometimes (or more often) forgetting to take the medication. ${ }^{16}$

\section{Structural support}

Structural support was assessed by the size of an individual's social network using the abbreviated (6-item) Lubben Social Network Scale (LSNS). ${ }^{17}$ The LSNS was developed to evaluate the number of familial and friendship ties maintained by an older adult population. ${ }^{18}$ The LSNS poses three questions each about familial and friendship ties, including how many relatives and/or friends one sees or hears from at least monthly, feels close enough with to call on for help and feels at ease with to talk about private matters. Scores range from 0 to 30 ; and participants were classified as 
socially connected (score $\geq 12$ ) or socially isolated (score $<12$ ) following scoring guidance. ${ }^{17}$

\section{Functional support}

Functional support was measured as the frequency of tangible medication social support with the Support with Medication Management Scale (SMMS). The SMMS was developed by the study team to assess the extent to which participants receive tangible assistance from family, friends or paid caregivers in managing their health and taking medicines. A new scale was developed after identifying a void in existing assessments that capture the frequency of supportive behaviours related to medication self-management. The item development was informed by the Medication Self-Management model, which proposes a series of cyclical tasks associated with taking prescription medications; to gain the therapeutic benefits of the medication individuals must 1) fill prescriptions in a timely manner, 2) understand medication instructions, 3) organise and consolidate their regimen to the most efficient, safe daily schedule, 4) take each medication as prescribed, 5) monitor medication use and report any side effects or concerns to their provider, 6) sustain use over time. ${ }^{19}$ The study team, which included experts in primary care, medication safety and management and health services research generated possible items and refined each question through a series of discussions.

The original scale included 16 items which assessed received support in a range of behaviours related to taking medication, including attending doctor visits, calling the pharmacy, picking up medication, assistance with medication organisation and reminders to take asthma and all medications (online supplementary table 1). Participants are asked the frequency with which they receive assistance for each item; response are on a 5-point Likert scale.

The distribution of responses for each item in the SMMS was reviewed and any item with minimal variation $(\geq 85 \%$ of participants responded never or rarely) was dropped; eight items were included in the total score. We conducted a factor analysis using orthogonal rotation to confirm the scale was measuring a single latent variable, and measured Cronbach's alpha to assess internal consistency. The eight items loaded onto one factor (Eigen: 4.37, factor loadings range $0.68-0.81$ ), and $\alpha=0.90$. We also conducted a confirmatory factor analysis using orthogonal rotation to assess item convergence and discrimination with other scales (ADLs, structural support), in which all items from the individual scales loaded onto their respective scales. SMMS scores were summed and we used a median split to dichotomise the level of assistance provided (infrequent support, frequent support).

\section{Covariates}

Self-reported gender, age, race/ethnicity, monthly household income, educational attainment and marital status were collected. A measure of asthma history (number of years since diagnosis) was also included since longterm experience with asthma could affect asthma self-management behaviours. Beliefs about asthma controller medications were assessed using the Beliefs about Medications Questionnaire, a 10-item questionnaire that measures a patient's beliefs about drugs related to two domains: concerns and necessity. ${ }^{20}$ Health literacy was measured using the Short Test of Functional Health Literacy in Adults. ${ }^{21}$ Health status was measured via self-reported number of chronic conditions and limitations in activities of daily living (ADLs) using the Katz Index of ADLs. ${ }^{22}$ In order to account for the potential confounding effect of health status and in recognition that both chronic conditions and physical function are important determinants of health status, ${ }^{23}$ we created a composite variable to identify individuals in poor health status; patients were classified as poor health status if they were diagnosed with five or more chronic conditions or were classified as having one or more limitation in ADLs.

\section{Patient and public involvement}

Patients and the public were not involved in the design or conduct of this research study.

\section{Statistical analysis}

The sample size for the ABLE cohort was based on the primary outcomes of the main analysis. ${ }^{324}$ Analyses were limited to participants who were prescribed an asthma controller medication and had complete functional and structural support assessments $(\mathrm{n}=338)$. Participants who were not prescribed an asthma controller medication or incomplete functional and structural support assessments were more likely to have limited health literacy, and have low income $(\mathrm{p}<0.05)$; no other differences in demographic characteristics were observed.

First, we conducted $\chi^{2}$ and t-tests to examine differences in the primary independent variables (structural support, functional support) and demographic and health status measures. Next, we conducted $\chi^{2}$ analyses to examine the relationship between structural support, functional support and adherence to asthma controller medication (measured via dose counts and self-report). Unadjusted and adjusted logistic regression models were conducted to examine the independent associations of structural and function support and adherence to asthma controller medications. Good adherence was the referent category. In order to account for potential confounding of differences in health status, we repeated the analysis stratified by the poor health status indicator. We subsequently conducted a Mantel-Haenszel test for homogeneity of OR to test if the association of functional support with medication adherence was significantly different by health status. Structural and functional support were dichotomised to ease interpretation, as a one-unit change on these scales is uninterpretable. As dichotomising can lead to loss of information, and other problems, ${ }^{25}$ a sensitivity analysis was run to examine the relationship between continuous versions of these variables and adherence. Model parameter estimates are presented in online supplementary table 2 , and similar trends were observed. 
Table 1 Differences in demographic and health characteristics between functional and structural measures of social relationships

\begin{tabular}{|c|c|c|c|c|c|c|c|}
\hline & \multirow[b]{2}{*}{$\begin{array}{l}\text { All participants } \\
(n=338)\end{array}$} & \multicolumn{2}{|c|}{ Structural support } & \multirow[b]{2}{*}{$P$ value } & \multicolumn{2}{|c|}{ Functional support } & \multirow[b]{2}{*}{$P$ value } \\
\hline & & $\begin{array}{l}\text { Socially } \\
\text { connected } \\
(\mathrm{n}=266)\end{array}$ & $\begin{array}{l}\text { Socially } \\
\text { isolated } \\
(n=72)\end{array}$ & & $\begin{array}{l}\text { Infrequent } \\
\text { support } \\
(\mathrm{n}=189)\end{array}$ & $\begin{array}{l}\text { Frequent } \\
\text { support } \\
(n=149)\end{array}$ & \\
\hline Age (years), n (\%) & & & & 0.54 & & & 0.15 \\
\hline $60-64$ & $150(44.5)$ & $119(44.9)$ & $31(43.1)$ & & $93(49.2)$ & 57 (38.5) & \\
\hline $65-69$ & $82(24.3)$ & $67(25.3)$ & $15(20.8)$ & & $42(22.2)$ & $40(27.0)$ & \\
\hline $70+$ & $105(31.2)$ & $79(29.8)$ & $26(36.1)$ & & $54(28.6)$ & $51(34.5)$ & \\
\hline Sex, female, n (\%) & $284(84.0)$ & $223(83.8)$ & $61(84.7)$ & 0.86 & $150(79.4)$ & 134 (89.9) & 0.008 \\
\hline Race, \% & & & & 0.001 & & & $<0.001$ \\
\hline Non-Hispanic black & $111(32.8)$ & $90(33.8)$ & $21(29.2)$ & & $59(31.2)$ & $52(34.9)$ & \\
\hline Non-Hispanic white & $81(24.0)$ & $74(27.8)$ & $7(9.7)$ & & 69 (36.5) & $12(8.1)$ & \\
\hline Hispanic & $130(38.5)$ & $91(34.2)$ & $39(54.2)$ & & $52(27.5)$ & 78 (52.3) & \\
\hline Other & $16(4.7)$ & $11(4.1)$ & $5(6.9)$ & & $9(4.8)$ & $7(4.7)$ & \\
\hline Education, n (\%) & & & & $<0.001$ & & & $<0.001$ \\
\hline Less than high school & $112(33.1)$ & 75 (28.2) & $37(51.4)$ & & $44(23.3)$ & $68(45.6)$ & \\
\hline High school graduate & 57 (16.9) & $41(15.4)$ & $16(22.2)$ & & 25 (13.2) & $32(21.5)$ & \\
\hline Some college & $70(20.7)$ & $64(24.1)$ & $6(8.3)$ & & $45(23.8)$ & $25(16.8)$ & \\
\hline College graduate & 99 (29.3) & $86(32.3)$ & $13(18.1)$ & & 75 (39.7) & $24(16.1)$ & \\
\hline $\begin{array}{l}\text { Monthly income (US\$), } n \\
\text { (\%) }\end{array}$ & & & & $<0.001$ & & & $<0.001$ \\
\hline$\leq 1350$ & $173(52.4)$ & $121(46.5)$ & $52(74.3)$ & & $74(39.8)$ & $99(68.7)$ & \\
\hline $1351-3000$ & $80(24.3)$ & $69(26.5)$ & $11(15.7)$ & & $56(30.1)$ & $24(16.7)$ & \\
\hline$\geq 3001$ & 77 (23.3) & $70(27.0)$ & $7(10.0)$ & & $56(30.1)$ & $21(14.6)$ & \\
\hline Health literacy, n (\%) & & & & 0.001 & & & $<0.001$ \\
\hline Limited & $108(31.4)$ & $75(28.7)$ & $33(50.0)$ & & $43(22.8)$ & $65(47.1)$ & \\
\hline Adequate & $219(68.6)$ & $186(71.3)$ & $33(50.0)$ & & $146(77.2)$ & 73 (52.9) & \\
\hline Married, n (\%) & $105(31.1)$ & $91(34.2)$ & $14(19.4)$ & 0.02 & 61 (32.3) & $44(29.5)$ & 0.59 \\
\hline ADL limitation, $n(\%)$ & & & & 0.03 & & & $<0.001$ \\
\hline 0 & $237(70.3)$ & $194(73.2)$ & $43(59.7)$ & & $154(81.9)$ & $83(55.7)$ & \\
\hline$\geq 1$ & $100(29.7)$ & $71(26.8)$ & $29(40.3)$ & & $34(18.1)$ & $66(44.3)$ & \\
\hline $\begin{array}{l}\text { \# Chronic conditions, } \\
\text { mean (SD) }\end{array}$ & $3.8(1.6)$ & $3.6(1.5)$ & $4.8(1.6)$ & $<0.001$ & $3.4(1.4)$ & $4.4(1.4)$ & $<0.001$ \\
\hline Poor health status, n (\%) & $180(46.6)$ & $110(41.5)$ & $47(62.3)$ & $<0.001$ & $58(30.9)$ & $99(66.4)$ & $<0.001$ \\
\hline BMQ: necessity, mean (SD) & $12.9(4.6)$ & $13.0(4.5)$ & $12.7(4.4)$ & 0.66 & $13.2(4.7)$ & $12.5(4.2)$ & 0.24 \\
\hline BMQ: concerns, mean (SD) & $16.1(4.4)$ & $16.6(4.2)$ & $16.0(4.6)$ & 0.25 & $17.3(4.2)$ & $15.5(4.2)$ & $<0.001$ \\
\hline
\end{tabular}

ADL, activities of daily living; BMQ, Beliefs about Medications Questionnaire.

All analyses were performed using STATA V.13.1 (College Station, Texas, USA).

\section{RESULTS}

The mean age of the sample was $67( \pm 6.5)$ years. There was racial and ethnic diversity (Hispanic (38\%), black $(33 \%)$, white $(24 \%))$ (table 1$)$, and the majority of participants were low-income, $52 \%$ reported monthly incomes $\leq$ US $\$ 1350$ and female $(84 \%)$. There were very low rates of medication adherence to asthma controller medication, with $36.3 \%$ reported good adherence when measured via dose counts, and $38.6 \%$ reported good adherence by self-report assessments. The agreement between the two forms of collection was $67.7 \% \quad(\kappa=0.32, \mathrm{p}<0.001)$. There were no significant differences in any demographic variables or outcomes between those who did and did not complete the adherence assessment by dose counts ( $p>0.05)$.

The distribution of responses to the SMMS are presented in table 2. A third of participants reported that someone accompanied them to medical appointments 
Table 2 Distribution of responses to items in the Support with Medication Management Scale assessment of functional social support

\begin{tabular}{lr}
\hline Question: how often does someone else: & $\mathbf{n ~ ( \% )}$ \\
\hline Come with to medical appointments & $67(19.8)$ \\
\hline Always & $15(4.4)$ \\
\hline Often & $47(13.9)$ \\
\hline Sometimes & $35(10.4)$ \\
\hline Rarely & $174(51.5)$ \\
\hline Never & \\
Call physician when running out of medicines & $33(9.8)$ \\
\hline Always & $7(2.1)$ \\
\hline Often & $26(7.7)$ \\
\hline Sometimes & $16(4.7)$ \\
\hline Rarely & $256(75.7)$ \\
\hline Never & \\
\hline Call pharmacy for refills & $43(12.7)$ \\
\hline Always & $9(2.7)$ \\
\hline Often & $27(8.0)$ \\
\hline Sometimes & $22(6.5)$ \\
\hline Rarely & $237(70.1)$ \\
\hline Never & \\
\hline Bring prescriptions to pharmacy to be filled & \\
\hline
\end{tabular}

Bring prescriptions to pharmacy to be filled

$\begin{array}{lc}\text { Always } & 55(16.3) \\ \text { Often } & 14(4.2) \\ \text { Sometimes } & 45(13.3) \\ \text { Rarely } & 31(9.2) \\ \text { Never } & 193(57.1) \\ \text { Pick up medicines at pharmacy } & \\ \text { Always } & 63(19.0) \\ \text { Often } & 13(4.0) \\ \text { Sometimes } & 63(19.0) \\ \text { Rarely } & 45(13.6) \\ \text { Never } & 147(44.4)\end{array}$

Remind to take asthma controller medicine

\begin{tabular}{lc} 
Always & $24(7.1)$ \\
Often & $5(1.5)$ \\
\hline Sometimes & $30(8.9)$ \\
Rarely & $23(6.8)$ \\
\hline Never & $256(75.7)$ \\
\hline Remind to take other medicines & $32(9.6)$ \\
\hline Always & $7(2.1)$ \\
\hline Often & $30(9.0)$ \\
\hline Sometimes & $22(6.6)$ \\
\hline Rarely & $244(72.8)$ \\
\hline Never & \\
\hline Ask physician what new medicines is for & $31(9.2)$ \\
\hline Always & Continued
\end{tabular}

\begin{tabular}{|lr|}
\hline Table 2 Continued & \\
\hline Question: how often does someone else: & $\mathbf{n}(\%)$ \\
\hline Often & $7(2.1)$ \\
\hline Sometimes & $19(5.6)$ \\
Rarely & $15(4.4)$ \\
Never & $266(78.7)$ \\
\hline
\end{tabular}

and brought prescription medicines to the pharmacy at least some of the time $(38.1 \%, 33.8 \%$, respectively). Nearly half $(42 \%)$ of participants reported that someone else picked up their medicines from the pharmacy at least some of the time. Participants received less assistance in terms of reminders to take medications; most reported that no one ever reminded them to take their asthma controller $(75.7 \%)$ or other $(72.8 \%)$ medication. Additionally, less than a quarter received assistance at least some of the time calling the physician when medicines were running low (19.6\%), calling the pharmacy for refills $(23.4 \%)$, or asking a physician what a new medicine is for $(16.9 \%)$.

The mean structural support score was 16.8 ( $\mathrm{SD}=6.4)$ (range $0-30$ ), and $21 \%$ were classified as socially isolated. Those who were socially isolated were more likely to identify as Hispanic, have lower educational attainment, household income, health literacy one or more ADL impairment; diagnosed with more chronic conditions and be unmarried as compared with individuals who were socially connected $(\mathrm{p}<0.05)$. A weak, yet significant, negative correlation was found between the two measures of structural and functional support $(\mathrm{r}=-0.15, \mathrm{p}=0.005)$, indicating that those with fewer individuals in their social network reported greater frequency of tangible medication social support. Among the entire sample, a total of $42(12.4 \%)$ individuals who were identified as socially isolated also reported receiving frequent support with managing their medications.

Structural support was not associated with either measure of medication adherence (table 3). However, individuals who reported infrequent functional support had lower rates of poor medication adherence compared with those with frequent assistance managing medications (dose counts: $53.9 \%$ vs $71.1 \%$, p=0.002; self-report $56.7 \%$ vs $72.7 \%, \mathrm{p}=0.007$ ).

These associations remained in multivariable adjusted analyses (table 4) for medication adherence assessed by dose counts (OR $0.51,95 \%$ CI 0.26 to 0.98 ), but not by self-report (OR $0.81,95 \%$ CI 0.44to 1.48), indicating that those with infrequent functional support have a decreased odds of non-adherence compared with their counterparts with frequent functional support. We also conducted analyses stratified by health status (table 4); the test for homogeneity of OR was non-significant (dose counts: $\chi^{2}=0.69, \mathrm{p}=0.41$; self-report: $\chi^{2}=0.36, \mathrm{p}=0.57$ ), indicating that the association between medication 
Table 3 Differences in adherence to asthma controller medications between measures of structural and functional support

\begin{tabular}{|c|c|c|c|c|c|c|c|}
\hline \multirow[b]{2}{*}{ Variable } & \multirow[b]{2}{*}{$\begin{array}{l}\text { All } \\
\text { participants } \\
(n=338)\end{array}$} & \multicolumn{2}{|c|}{ Structural support } & \multicolumn{3}{|c|}{ Functional support } & \multirow[b]{2}{*}{$\mathbf{P}$ value } \\
\hline & & $\begin{array}{l}\text { Socially } \\
\text { connected } \\
(n=266)\end{array}$ & $\begin{array}{l}\text { Socially } \\
\text { isolated } \\
(n=72)\end{array}$ & $P$ value & $\begin{array}{l}\text { Infrequent } \\
\text { support } \\
(n=189)\end{array}$ & $\begin{array}{l}\text { Frequent } \\
\text { support } \\
(n=149)\end{array}$ & \\
\hline $\begin{array}{l}\text { Adherence via dose counts, } \\
\text { n (\%) }\end{array}$ & & & & 0.21 & & & 0.002 \\
\hline Good adherence & 97 (36.3) & $81(38.2)$ & $16(29.1)$ & & $84(46.2)$ & $41(28.9)$ & \\
\hline $\begin{array}{l}\text { Adherence via self-report, } \\
\text { n (\%) }\end{array}$ & & & & 0.17 & & & 0.007 \\
\hline Good adherence & $125(38.6)$ & $103(40.6)$ & $22(31.4)$ & & $65(43.3)$ & $32(27.4)$ & \\
\hline Poor adherence & $199(61.4)$ & $151(59.5)$ & $48(68.6)$ & & $85(56.7)$ & $85(72.7)$ & \\
\hline
\end{tabular}

adherence and functional social support was not significantly different by health status.

\section{DISCUSSION}

Theoretical models of social support suggest that social support influences health outcomes through psychological and behavioural pathways. ${ }^{7}$ Despite this proposed model, few studies have tested the pathway between social support and health behaviours in the form of adherence to medications among socioeconomically and racially/ethnically diverse older adults. Social support may be of great benefit to older adults who frequently manage complex multidrug regimens; however, the multidimensional nature of social support challenges the identification of the most relevant domains. ${ }^{78}$ As few studies have specifically targeted a more socioeconomically disadvantaged older population, we tested associations between functional and structural support with adherence to medication among this population.

Table 4 Differences in poor adherence to asthma controller medications between measures of structural and functional support

\begin{tabular}{|c|c|c|c|c|}
\hline & \multicolumn{2}{|c|}{ Dose count of poor medication adherence } & \multicolumn{2}{|c|}{ Self-report of poor medication adherence } \\
\hline & Unadjusted & Adjusted & Unadjusted & Adjusted \\
\hline & OR $(95 \% \mathrm{Cl})$ & OR $(95 \% \mathrm{Cl})$ & OR $(95 \% \mathrm{Cl})$ & OR $(95 \% \mathrm{Cl})$ \\
\hline \multicolumn{5}{|c|}{ Structural social support } \\
\hline Socially isolated & $1.51(0.79$ to 2.87$)$ & 1.80 (0.81 to 3.99$)$ & $1.48(0.85$ to 2.61$)$ & $0.86(0.42$ to 1.77$)$ \\
\hline \multicolumn{5}{|l|}{ Socially connected } \\
\hline \multicolumn{5}{|c|}{ Functional social support } \\
\hline \multicolumn{5}{|c|}{ Pooled } \\
\hline Infrequent support & $0.49(0.29 \text { to } 0.82)^{\star \star}$ & $0.51(0.26 \text { to } 0.98)^{*}$ & $0.47(0.30 \text { to } 0.75)^{\star \star}$ & 0.81 (0.44 to 1.48$)$ \\
\hline \multicolumn{5}{|l|}{ Frequent support } \\
\hline \multicolumn{5}{|c|}{ Stratified by health status } \\
\hline \multicolumn{5}{|c|}{ Poor health status } \\
\hline Infrequent support & $0.37(0.15 \text { to } 0.82)^{*}$ & $0.32(0.11 \text { to } 0.92)^{\star}$ & 0.67 (0.32 to 1.28$)$ & $1.18(0.45$ to 3.10$)$ \\
\hline \multicolumn{5}{|l|}{ Frequent support } \\
\hline \multicolumn{5}{|c|}{ Adequate health status } \\
\hline Infrequent support & 0.59 (0.28 to 1.27$)$ & $0.47(0.17$ to 1.29$)$ & $0.47(0.23 \text { to } 0.95)^{\star}$ & $0.70(0.29$ to 1.73$)$ \\
\hline \multicolumn{5}{|l|}{ Frequent support } \\
\hline \multicolumn{5}{|c|}{$\begin{array}{l}\text { Adjusted analyses controlling for age, race/ethnicity, income, education, health literacy, number of years with asthma, limitations in ADL and } \\
\text { number of chronic conditions, beliefs about asthma controller medications. } \\
\text { In order to further account for confounding by health status and subsequent need of functional support, we stratified by poor health status } \\
\text { (diagnosed with five or more chronic conditions or reported one or more ADL impairment). Adjusted stratified analyses were adjusted for age, } \\
\text { race/ethnicity, income, education, health literacy, number of years with asthma, beliefs about asthma controller medications. } \\
{ }^{*} \mathrm{p}<0.05 ;{ }^{* \star} p<0.01 ;{ }^{* \star \star} p<0.001 \text {. } \\
A D L, \text { activities of daily living. }\end{array}$} \\
\hline
\end{tabular}


In a sample of socioeconomically and culturally diverse older adults with asthma, we did not observe an association between adherence to asthma controller medications and structural support. Our findings are congruous with related literature that has not observed consistent associations between medication adherence and structural measures of support, ${ }^{9}$ as well as broader self-management behaviours. ${ }^{10}{ }^{11}$ Not surprising, these findings suggest that the presence of individuals within older adults support network, independent of their functional contributions, may be an oversimplification of the mechanism through which social support influences health behaviours.

We hypothesised that infrequent functional support with medication management tasks would be associated with poorer medication adherence. To the contrary, we observed the inverse relationship, that receipt of more frequent functional support with medication management tasks was associated with poorer adherence to asthma controller medications. Reviewing the distribution of responses among the items within the SMMS, we observed that the greatest rates of assistance were among more intensive yet less frequent tasks, such as accompanying participants to medical appointments or picking up medications from the pharmacy. Conversely, tasks that occurred on a daily basis, such as reminders to take medicines, occurred less often. A series of sequential behaviours must occur to accurately adhere to medications, including filling and picking up a prescription, organising and planning when to take the medication and actually taking the correct medication dosage ${ }^{19}$ and older adults may require more regular assistance throughout the continuum of steps.

Our SMMS was designed to measure received functional support, and true to the multidimensional nature of social support, there are distinctions between perceived versus received support. Perceived support encompasses one's potential access to social support, while received support refers to one's utilisation of support resources ${ }^{26}$ Previous literature specific to received functional tangible support presents similar findings and potential explanations. ${ }^{7}$

One explanation for this inverse relationship is that people who have previously demonstrated poor medication adherence or greater health needs require, and likely receive, more functional support. We observed associations between comorbidity and measures of disability with functional support; however in analyses stratified by health status, we did not observe significant variations in the association between functional social support and medication adherence. Additionally, our pooled analysis included measures of health status to control for potential confounding. While our cross-sectional study design prevents us from understanding the directionality of the relationship or isolate the need for functional support, similar longitudinal investigations have found even when controlling for baseline health status, receipt of tangible support was associated with higher rates of prospective mortality. ${ }^{27-29}$ More recent investigations of a cohort study of English civil servants found that greater levels of tangible functional support was associated with poorer physical health. ${ }^{30}$ The authors also tested the possible bidirectional relationship between social support and health, while the results overall provided support for a bidirectional relationship between physical health and social support, this relationships did not remain in within-person analyses. ${ }^{30}$ These findings overall suggest there are other mechanisms at work in addition to prior health status.

We also observed significant associations between socioeconomic factors and functional support. An alternative explanation for our findings may be that individuals who report greater levels of received support are also more likely to experience socioeconomic stressors, which in turn mobilises the provision of support. ${ }^{26}{ }^{31}$ Ethnographic research in poor communities has observed among family members or acquaintances a network of reciprocity and mutual obligation through which resources flow as a means to cope with significant adversity. ${ }^{32-34}$ It is therefore possible that among our low-income sample, individuals may receive more assistance in general due to existing practices to cope with repeated stressful circumstances. Considered with the observed negative correlation between social isolation and frequency of functional support, individuals who receive more functional support with their medications are likely relying on only a few people. Our measure did not capture who was providing this support, or the perceived adequacy of the received support, both of which may impact its effectiveness, and future research should further examine these dimensions.

These findings should be recognised in the context of several limitations. First, these were cross-sectional analyses and therefore we are limited in understanding directionality of these associations, and we cannot infer causality. Second, we conducted a secondary data analysis of a cohort of urban, predominantly female, older adults with asthma and our findings may not be generalisable to younger populations, in different disease contexts, or among an older male population. In addition, our measure of functional support was not previously validated; however, we were not aware of any medication-specific functional support measures. The SMMS demonstrated high internal reliability and acceptable construct validity. As this was a new measure, we used a median split to dichotomise some variables, and a clinically meaningful cut-off may provide additional utility. Our questions related to functional and structural support were broad by design and we did not inquire about who provided the support and the patient's perceived adequacy of the received support. Additionally, our outcome measurement of medication adherence had moderate agreement between the subjective and objective measurements. Lastly, to facilitate interpretation of our findings we dichotomised functional and structural support. We ran sensitivity analyses to examine the relationship between continuous versions of the variables and adherence. The trends of lower support being associated with poorer adherence was consistent, with the only exception being the adjusted model of functional support on dose count of poor adherence, in which we saw a similar trend, but it failed to reach statistical significance $(\mathrm{p}=0.06)$. 
These findings are an important contribution to the literature on social support and self-management behaviours as very few studies have been conducted in elderly, non-white or low-income samples. ${ }^{10}$ Our findings underscore the complex and multidimensional nature of social support and the mechanisms in which it operates. Further research is needed to better understand the manner in which functional support operates in relation to medication adherence among older adults.

\section{Author affiliations}

${ }^{1}$ General Internal Medicine and Geriatrics, Northwestern University, Chicago, Illinois, USA

${ }^{2}$ School of Public Health, University of Illinois at Chicago, Chicago, Illinois, USA

${ }^{3}$ Department of Preventive Medicine, Northwestern University, Chicago, Illinois, USA

${ }^{4}$ College of Nursing, University of Illinois at Chicago, Chicago, Illinois, USA

${ }^{5}$ Denver Health and Hospital Authority, Denver, Colorado, USA

${ }^{6}$ Icahn School of Medicine at Mount Sinai, New York City, New York, USA

${ }^{7}$ Department of General Internal Medicine, Northwestern University, Chicago, Illinois, USA

Contributors R0, MW, JW and AF contributed to the conception and design of the study. RO contributed to the data acquisition. RO, JH-B, MMK, KE, RH-W, MW and $\mathrm{AF}$ contributed to the data analysis and interpretation. All authors provided critical revision for intellectual content and final approval of the manuscript.

Funding This study was supported by a grant from the National Heart, Lung and Blood Institute (R01HL096612).

Competing interests MW has unrestricted research grants from Merck, Sharpe, Dohme and Eli Lily; has consulted for Luto UK and Pfizer and received honoraria from MedLearning Group, New York University. JW has received consulting honorarium from Quintiles, AstraZenaca, Sanofi and Merck, and research grants from Sanofi and Quorum.

Patient consent for publication Not required.

Ethics approval The study was approved by the Institutional Review Boards of the Mount Sinai School of Medicine and Northwestern University.

Provenance and peer review Not commissioned; externally peer reviewed.

Data availability statement No data are available.

Open access This is an open access article distributed in accordance with the Creative Commons Attribution Non Commercial (CC BY-NC 4.0) license, which permits others to distribute, remix, adapt, build upon this work non-commercially, and license their derivative works on different terms, provided the original work is properly cited, appropriate credit is given, any changes made indicated, and the use is non-commercial. See: http://creativecommons.org/licenses/by-nc/4.0/.

\section{REFERENCES}

1. Naderi SH, Bestwick JP, Wald DS. Adherence to drugs that prevent cardiovascular disease: meta-analysis on 376,162 patients. Am J Med 2012;125:882-7.

2. Benner JS, Glynn RJ, Mogun $\mathrm{H}$, et al. Long-Term persistence in use of statin therapy in elderly patients. JAMA 2002;288:455-61.

3. Federman AD, Wolf MS, Sofianou A, et al. Self-Management behaviors in older adults with asthma: associations with health literacy. J Am Geriatr Soc 2014;62:872-9.

4. Gellad WF, Grenard JL, Marcum ZA. A systematic review of barriers to medication adherence in the elderly: looking beyond cost and regimen complexity. Am J Geriatr Pharmacother 2011;9:11-23.

5. Gellad WF, Haas JS, Safran DG. Race/ethnicity and nonadherence to prescription medications among seniors: results of a national study. $J$ Gen Intern Med 2007;22:1572-8.

6. Insel K, Morrow D, Brewer B, et al. Executive function, working memory, and medication adherence among older adults. $J$ Gerontol B Psychol Sci Soc Sci 2006;61:P102-P107.

7. Holt-Lunstad J, Uchino BN. Social Support and Health. In: Glanz K, Rimer BK, Viswanath K, eds. Health Behavior: Theory, Research, and Practice: John Wiley \& Sons, 2015: 183-242.
8. National Academies of Sciences E, Medicine. Accounting for social risk factors in Medicare payment: identifying social risk factors. Washington, DC: National Academies Press, 2017.

9. Scheurer D, Choudhry N, Swanton KA, et al. Association between different types of social support and medication adherence. Am J Manag Care 2012;18:e461-7.

10. Gallant MP. The influence of social support on chronic illness selfmanagement: a review and directions for research. Health Educ Behav 2003;30:170-95.

11. DiMatteo MR. Social support and patient adherence to medical treatment: a meta-analysis. Health Psychol 2004;23:207-18.

12. George J, Phun Y-T, Bailey MJ, et al. Development and validation of the medication regimen complexity index. Ann Pharmacother 2004;38:1369-76.

13. O'Conor R, Wolf MS, Smith SG, et al. Health literacy, cognitive function, proper use, and adherence to inhaled asthma controller medications among older adults with asthma. Chest 2015;147:1307-15.

14. Osterberg L, Blaschke T. Adherence to medication. N Engl J Med 2005;353:487-97.

15. Williams LK, Joseph CL, Peterson EL, et al. Patients with asthma who do not fill their inhaled corticosteroids: a study of primary nonadherence. J Allergy Clin Immunol 2007;120:1153-9.

16. Cohen JL, Mann DM, Wisnivesky JP, et al. Assessing the validity of self-reported medication adherence among inner-city asthmatic adults: the medication adherence report scale for asthma. Annals of Allergy, Asthma \& Immunology 2009;103:325-31.

17. Lubben J, Blozik E, Gillmann G, et al. Performance of an abbreviated version of the Lubben social network scale among three European community-dwelling older adult populations. Gerontologist 2006;46:503-13.

18. Lubben JE. Assessing social networks among elderly populations. Fam Community Health 1988;11:42-52.

19. Bailey SC, Oramasionwu CU, Wolf MS. Rethinking adherence: a health literacy-informed model of medication self-management. $J$ Health Commun 2013;18(Suppl 1):20-30.

20. Horne R, Weinman J, Hankins M. The beliefs about medicines questionnaire: the development and evaluation of a new method for assessing the cognitive representation of medication. Psychol Health 1999;14:1-24.

21. Baker DW, Williams MV, Parker RM, et al. Development of a brief test to measure functional health literacy. Patient Educ Couns 1999;38:33-42.

22. Katz S, Ford AB, Moskowitz RW, et al. Studies of illness in the aged. The index of ADL: a standardized measure of biological and psychosocial function. JAMA 1963;185:914-9.

23. McDowell I. Measuring health: a guide to rating scales and questionnaires. USA: Oxford University Press, 2006.

24. Soones TN, Lin JL, Wolf MS, et al. Pathways linking health literacy, health beliefs, and cognition to medication adherence in older adults with asthma. J Allergy Clin Immunol 2017;139:804-9.

25. Altman DG, Royston P. The cost of dichotomising continuous variables. BMJ 2006;332.

26. Uchino BN. Understanding the links between social support and physical health: a life-span perspective with emphasis on the separability of perceived and received support. Perspect Psychol Sci 2009;4:236-55.

27. Forster LE, Stoller EP. The impact of social support on mortality: a seven-year follow-up of older men and women. $J$ App/ Gerontol 1992;11:173-86.

28. Krause N. Received support, anticipated support, social class, and mortality. Res Aging 1997;19:387-422.

29. Kaplan GA, Wilson TW, Cohen RD, et al. Social functioning and overall mortality: prospective evidence from the Kuopio ischemic heart disease risk factor study. Epidemiology 1994;5:495-500.

30. Hakulinen C, Pulkki-Råback L, Jokela M, et al. Structural and functional aspects of social support as predictors of mental and physical health trajectories: Whitehall II cohort study. J Epidemiol Community Health 2016;70:710-5.

31. Barrera M. Distinctions between social support concepts, measures, and models. Am J Community Psychol 1986;14:413-45.

32. Desmond M. Disposable ties and the urban poor. Am J Sociol 2012;117:1295-335.

33. Desmond M. Evicted: poverty and profit in the American City: Broadway books, 2016

34. Stack CB. All our kin: strategies for survival in a black community. Basic Books, 1975. 